Available online at www.eccomasproceedia.org

Eccomas Proceedia COMPDYN (2021) 258-267

ECCOMAS

Proceedia
COMPDYN 2021

$8^{\text {th }}$ ECCOMAS Thematic Conference on Computational Methods in Structural Dynamics and Earthquake Engineering M. Papadrakakis, M. Fragiadakis (eds.) Streamed from Athens, Greece, 28 - 30 June 2021

\title{
MODELING STRATEGIES FOR NON-LINEAR SEISMIC ANALYSES: COMPARISON AMONG EFM AND FEM RESULTS ON AN EXISTING URM CASE STUDY
}

\author{
M. Pegoraro ${ }^{1}$, E. Saler ${ }^{2}$, M. Salvalaggio ${ }^{1}$ and M.R. Valluzzi $^{1}$ \\ ${ }^{1}$ Department of Cultural Heritage, University of Padova \\ Piazza Capitaniato 7, 35139 Padova, Italy \\ marco.pegoraro@dicea.unipd.it, matteo.salvalaggio@unipd.it,mariarosa.valluzzi@unipd.it \\ ${ }^{2}$ Department of Geosciences, University of Padova \\ via Gradenigo 6, 35131 Padova, Italy \\ elisa.saler@unipd.it
}

\begin{abstract}
Italian building heritage is widely composed of masonry buildings, whose characteristics largely vary depending on geographical location, construction techniques and materials typology. This type of structures has shown a high vulnerability to horizontal loads that must not be ignored, especially due to the high seismic hazard of Italian territory. Hence, appropriate numerical models are required to assess the complex structural behavior of unreinforced masonry (URM) existing structures, implementing the non-linear behavior of both materials and structure.

In this framework, two different approaches have been widely acknowledged: the Equivalent Frame Model (EFM) and the continuum Finite Element Model (FEM). This paper presents the application and comparison of these modeling strategies to an URM building dating back to XVII century, located in the Italian Alpine region (Roana, Vicenza). Non-linear static analyses were carried out by means of the software 3Muri (EFM), DIANA FEA and Midas FEA$N X$ (FEM). Results were compared in terms of ultimate resistance, capacity, ductility, and evolution of the damage state. Finally, assessment of the global behavior was carried out according to the Italian seismic code, pointing out the differences of the two approaches. Results showed that the EFM appears to be more conservative than FEM.
\end{abstract}

Keywords: Masonry buildings, Seismic vulnerability assessment, Non-linear static analysis, Finite Element Model, Equivalent Frame Model. 


\section{INTRODUCTION}

The importance of preserving the Cultural Heritage in Italy has become more and more important, even due to the seismic events, which interested Italian territory [1]. The complexity of masonry structures, which widely compose built heritage, derives from its nature, being an extremely non-homogeneous material, whose properties vary depending on units and binder characteristics, assembling techniques, geometric layout. Computational methods can be helpful for taking into account some uncertainties, which affect the structural behavior and therefore are becoming more and more essential for the seismic assessment of unreinforced masonry (URM) structures.

This paper aims to compare various modelling strategies applied to an existing URM building in north Italy (Veneto region). The models, based on different approaches for the non-linear behavior of both materials and structure, were compared through pushover analyses, which are able to represent the global structural behavior, providing an estimation for the structure's capacity. For this approach to be valid, the assumption of "box behavior" has to be made, thus considering only in-plane resistance for masonry panels and excluding the activation of out-of-plane mechanisms, which could lead to local collapses.

The results were also processed in terms of Near-Collapse PGA capacity, in order to evaluate how the different modelling strategies can affect seismic assessment.

\subsection{Numerical modeling of masonry structures}

Two of the most acknowledged modeling strategies for masonry structures are the Equivalent Frame Model (EFM) and the Finite Element Model (FEM) approaches [2]. EFM is based on the discretization of masonry walls through three different macro-elements: piers, spandrels, and rigid nodes. This subdivision idealizes a frame structure where piers and spandrels are connected through un-deformable elements (rigid nodes), while non-linear properties are lumped at hinge elements. This method is subject to multiple uncertainties, regarding the frame schematization and non-linear hinges behavior [3]. It is indicated for the in-plane analysis of regular structures [4], since the out-of-plane behavior is not considered [5].

FEM can provide more detailed discretization, yet it presents a higher computational cost. Different approaches can be used in FE masonry modeling [6], depending on the complexity and purposes of the analyses. A relatively simple yet effective approach is the continuum modeling, in which the heterogeneous characteristics of masonry (i.e., resistant units and binder) are merged into a homogeneous one, and non-linearities are uniformly distributed. This method allows creating complex models able to identify out-of-plane mechanisms and more accurate crack patterns [7].

\section{2 "La Cattedra" Case Study}

The case study is part of "La Cattedra" complex, located in Canove di Roana (province of Vicenza), in the Italian Alpine region, about $1000 \mathrm{~m}$ AMSL. It corresponds to the older portion of the complex (Figure 1a), dating back to XVI century and it is characterized by a rectangular layout of about $10 \mathrm{~m} \times 13 \mathrm{~m}$, split in half by a central wall (Figure 1b). The building is adjacent to the remaining complex on the north side. It is a regular three-story building with the arrangement of the windows on three distinct rows. The main entrance is centered on the eastern façade, whereas the inner stairs are placed on the opposite side.

Due to the lack of a particular economic value, the complex underwent numerous renovations, which altered the original layout. For this reason, experimental investigations had to be carried out to identify the structural elements of the building and determine their physical parameters. 


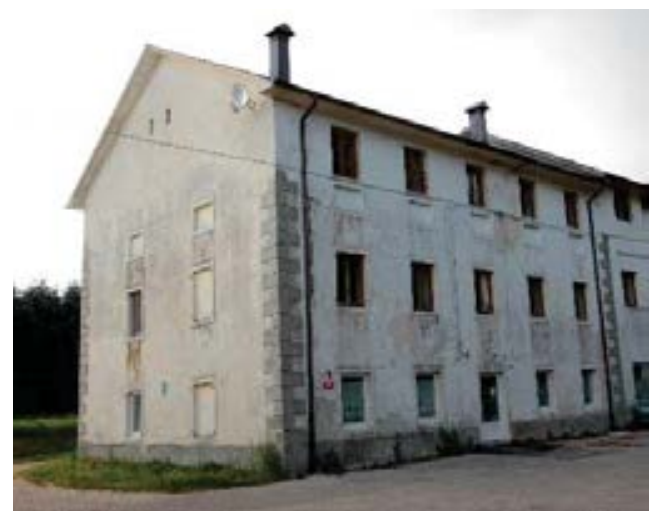

a)

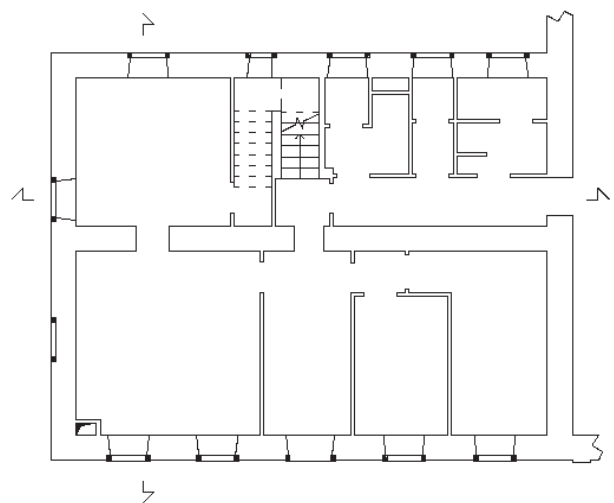

b)

Figure 1: a) Picture of 'La Cattedra' case study, b) plan scheme of the case study.

The experimental investigation campaign was carried out in 2019 implementing semidestructive and non-destructive tests. Firstly, scarifications were realized on different spots of the main walls, to identify the masonry type, detecting a stratigraphic composition; the lower portion is characterized by a local calcareous stone block (Biancone) masonry, whereas the upper section presents a hollow clay block one, due to a superelevation intervention realized on the last century. Walls' thickness varies from about $70 \mathrm{~cm}$ on the bottom to $60 \mathrm{~cm}$ on top of the building.

Two types of horizontal structures were detected: RC with slab for the first two floors, and $\mathrm{RC}$ without slabs for the third floor and the roof.

For the identification of masonry properties, both IQM (masonry quality index) analyses [8] and penetrometer tests on mortar samples were carried out: a very poor mortar was detected, especially for the stone masonry, while the characteristics improve for the block one.

\section{MODEL GENERATION}

The numerical models were developed via 3MURI (EFM), DIANA FEA and MIDAS FEA $\mathrm{NX}+($ FEA) (Figure 3), which represent some of the most common tools for EFM and FEM analyses of URM structures.

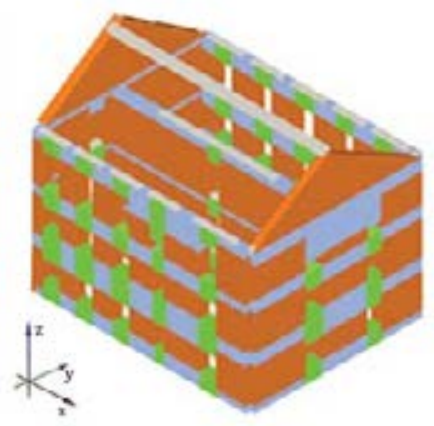

[a]

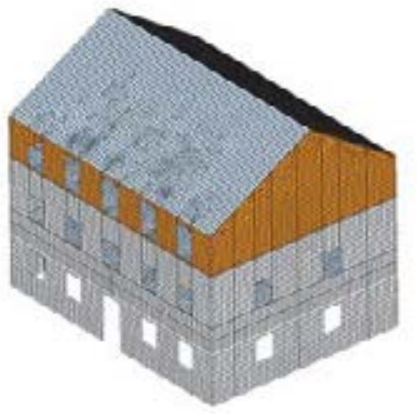

[b]

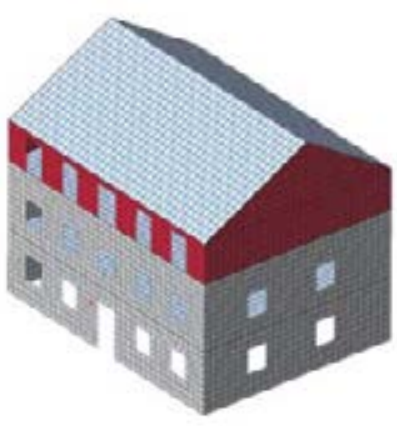

[c]

Figure 3: Numerical models: 3MURI (a), DIANA (b) and MIDAS (c) 


\subsection{EFM model}

3MURI software [9] was used for the EFM modeling [10], allowing the automatic mesh generation. Material's properties assigned for masonry elements (Table 1) were defined from the Italian seismic code [11] and the experimental investigations previously described. The non-linear properties, different for piers and spandrels, were described by two collapse criteria, related to a flexural and a shear behavior. The constitutive laws adopted for each criterion presents a bilinear behavior without hardening, followed by progressive resistance softening (Figure 4). A 50\% reduced stiffness is generally suggested [11] to simulate the cracked conditions of masonry elements. However, this assumption strongly affects the initial global stiffness, and it's commonly accepted the use of un-reduced values, since adopted parameters are already conservative, deriving from code tables and being already reduced by safety factors [12]. Hence, having to compare different modelling strategies, uncracked stiffness was considered.

Floors were modeled as 4-noded orthotropic plane strain elements, whose elastic properties for both types are listed in Table 2 .

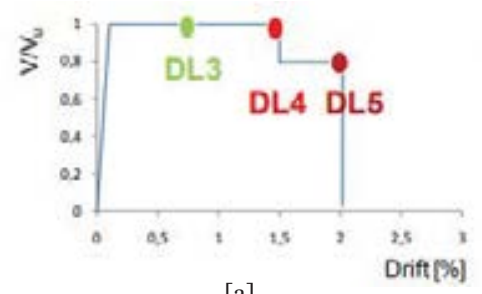

[a]

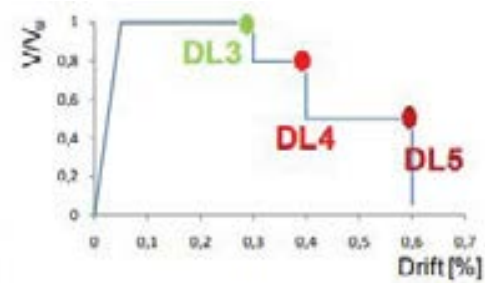

$[\mathrm{b}]$

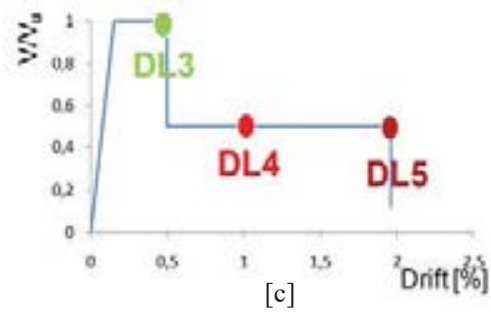

$[\mathrm{c}]$

Figure 4: Constitutive laws adopted for EFM in 3MURI: a) flexural and b) shear behavior for piers, c) lintel model for spandrels (DL: Damage Level) [13].

\subsection{FEM model}

FEM analyses were carried out by means of two software: DIANA FEA [14] and MIDAS FEA NX $+[15]$, referring to a continuum approach. In both cases, masonry walls were modeled through curved shell elements, considering the material as nonlinear isotropic. For the non-linear behavior of masonry, the smeared crack approach was chosen, originally developed for concrete [16] and later adapted to masonry. The parameters which characterize this model (Total Strain Based Crack for DIANA, Concrete Smeared Crack for MIDAS) are the tensile $\left(\mathrm{f}_{\mathrm{t}}\right)$ and compressive $\left(\mathrm{f}_{\mathrm{c}}\right)$ ultimate stresses and the fracture energy values $\left(\mathrm{G}_{\mathrm{t}}\right.$ and $\left.\mathrm{G}_{\mathrm{c}}\right)$ to define the post-peak of the stress-strain curve. The behavior is described by a linear softening function in tension and a parabolic function in compression. In addition, a shear retention factor $(\beta)$ was defined. The parameters implemented for each masonry type in the FE model (Table 1), are equal for both FE models. As for the EF model, the reference values derive from Italian seismic code [11], in accordance with the results of experimental tests, while fracture energy values were suggested by scientific literature [17].

Floors were modeled as elastic orthotropic shell element and elastic properties, equal for EF model, are reported in Table 2. 


\begin{tabular}{l|cc|cc}
\hline \hline & \multicolumn{2}{|c|}{ EFM } & \multicolumn{2}{c}{ FEM } \\
\hline \hline Parameter & SB Masonry & HCB Masonry & SB Masonry & HCB Masonry \\
\hline $\mathrm{E}[\mathrm{MPa}]$ & 1740 & 4550 & 1740 & 4550 \\
$v$ & 0.25 & 0.25 & 0.25 & 0.25 \\
$\mathrm{~W}\left[\mathrm{kN} / \mathrm{m}^{3}\right]$ & 20 & 14 & 20 & 14 \\
\hline \hline Tens. function & - & - & Linear softening & Linear softening \\
$\mathrm{f}_{\mathrm{t}}[\mathrm{MPa}]$ & 0.018 & 0.037 & 0.018 & 0.037 \\
$\mathrm{G}_{\mathrm{t}}[\mathrm{N} / \mathrm{mm}]$ & - & - & 0.00135 & 0.0045 \\
\hline \hline Comp. function & - & - & Parabolic & Parabolic \\
$\mathrm{f}_{\mathrm{c}}[\mathrm{MPa}]$ & 1.12 & 1.85 & 1.12 & 1.85 \\
$\mathrm{G}_{\mathrm{c}}[\mathrm{N} / \mathrm{mm}]$ & - & - & 4.8 & 5 \\
\hline \hline$\beta$ & - & - & 0.01 & 0.01 \\
\hline \hline
\end{tabular}

Table 1: Mechanical parameter for masonry type in EFM and FEM model. SB: stone blocks; HCB: hollow clay blocks.

\begin{tabular}{lcc}
\hline Parameter & $\begin{array}{c}\text { RC floor } \\
\text { (with slab) }\end{array}$ & $\begin{array}{c}\text { RC floors } \\
\text { (without slab) }\end{array}$ \\
\hline $\mathrm{E}_{\mathrm{x}}[\mathrm{MPa}]$ & 39200 & 36000 \\
$\mathrm{E}_{\mathrm{y}}[\mathrm{MPa}]$ & 20000 & 0 \\
$\mathrm{G}_{\mathrm{xy}}[\mathrm{MPa}]$ & 8300 & 1000 \\
\hline
\end{tabular}

. Table 2: Mechanical parameter for floors types (equal for EFM and FEM)

\section{RESULTS}

The seismic assessment was carried out through modal and pushover analyses. These last, as stated by the Italian code [11], were performed for both principal directions, following two load profiles: proportional to mass distribution and proportional to mode shape. The results, consisting in four capacity curves for each model, permitted to evaluate the seismic vulnerability for the global structure in terms of peak ground acceleration (PGA).

\subsection{Modal analyses}

The models were firstly compared through eigenvalue analyses. Table 3 reports the results for the three models in terms of modal frequencies and participant mass percentage for each principal direction. The comparison shows a good correlation for the first modes, especially between the two FE models, whose frequencies are close. For higher modes, differences become more significant, although less important than former ones.

Observing mass participation percentages, the FE models present similar values (about $75 \%$ ), for the first two modes, corresponding to the main bending modes in $\mathrm{Y}$ and $\mathrm{X}$ direction, respectively. Major differences can be observed for the EF model, especially on the second and third modes, which both are oriented in X direction, although involving less dynamic mass. Thus, while FE models shows a global dynamic behavior, with participating masses lumped in the first modes, EF model does not. 


\begin{tabular}{c|ccc|ccc|ccc}
\hline \multirow{2}{*}{ MODE } & \multicolumn{3}{|c|}{ 3MURI } & \multicolumn{3}{c|}{ DIANA FEA } & \multicolumn{3}{c}{ MIDAS FEA NX+ } \\
\cline { 2 - 10 } & $\mathrm{f}[\mathrm{Hz}]$ & $\mathrm{mx}[\%]$ & $\mathrm{my}[\%]$ & $\mathrm{f}[\mathrm{Hz}]$ & $\mathrm{mx}[\%]$ & $\mathrm{my}[\%]$ & $\mathrm{f}[\mathrm{Hz}]$ & $\mathrm{mx}[\%]$ & $\mathrm{my}[\%]$ \\
\hline 1 & 6.059 & $0.1 \%$ & $80.8 \%$ & 6.286 & $0.0 \%$ & $75.6 \%$ & 6.329 & $0.0 \%$ & $77.4 \%$ \\
2 & 6.851 & $22.4 \%$ & $5.4 \%$ & 8.230 & $76.2 \%$ & $0.0 \%$ & 8.283 & $73.5 \%$ & $0.0 \%$ \\
3 & 7.418 & $56.1 \%$ & $1.2 \%$ & 9.779 & $2.2 \%$ & $0.0 \%$ & 9.430 & $5.1 \%$ & $0.0 \%$ \\
4 & 12.152 & $10.3 \%$ & $0.0 \%$ & 13.220 & $0.0 \%$ & $6.0 \%$ & 11.200 & $0.0 \%$ & $0.1 \%$ \\
5 & 16.367 & $0.0 \%$ & $0.4 \%$ & 15.483 & $0.0 \%$ & $0.0 \%$ & 13.001 & $0.0 \%$ & $2.8 \%$ \\
6 & 17.452 & $0.2 \%$ & $9.4 \%$ & 20.009 & $0.0 \%$ & $3.6 \%$ & 16.047 & $0.1 \%$ & $0.0 \%$ \\
7 & 19.508 & $4.6 \%$ & $1.4 \%$ & 20.119 & $4.5 \%$ & $0.0 \%$ & 16.638 & $0.0 \%$ & $1.9 \%$ \\
8 & 20.509 & $0.3 \%$ & $0.2 \%$ & 20.849 & $0.1 \%$ & $0.8 \%$ & 17.635 & $0.0 \%$ & $0.0 \%$ \\
9 & 21.716 & $2.2 \%$ & $0.3 \%$ & 21.361 & $0.7 \%$ & $0.1 \%$ & 18.728 & $0.0 \%$ & $0.7 \%$ \\
10 & 22.738 & $0.0 \%$ & $0.0 \%$ & 21.870 & $2.4 \%$ & $0.0 \%$ & 19.751 & $0.1 \%$ & $0.0 \%$ \\
\hline
\end{tabular}

Table 3: Results of modal analyses

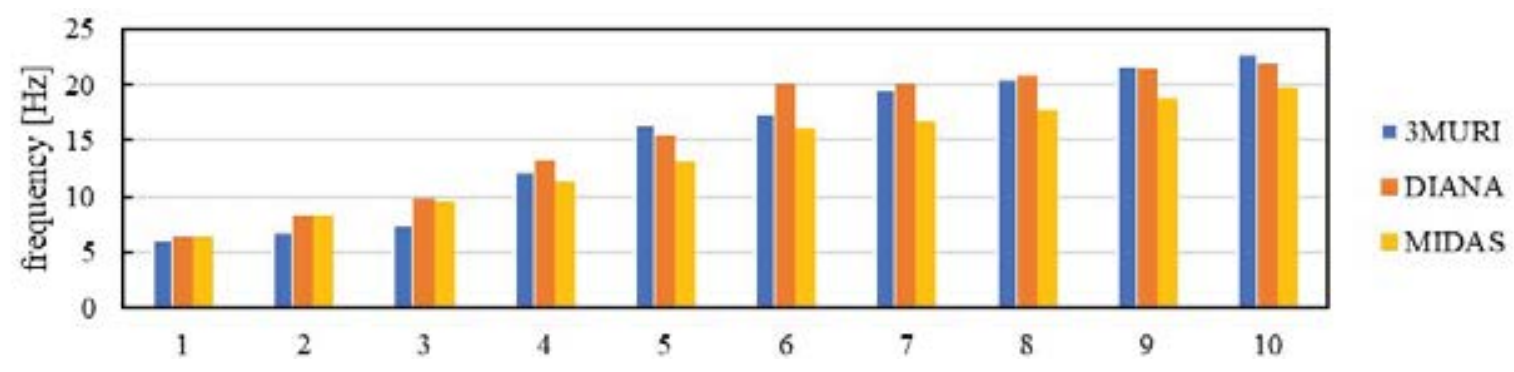

Figure 5: Comparison between modal frequencies

\subsection{Pushover analyses}

The capacity curves deriving from pushover analyses pointed out significant differences among the three models (Figure 6). The EF curves were characterized by two very distinct sections: the first elastic and the second almost perfectly horizontal. On the FE curves, instead, the transition between elastic and post-elastic behavior was less defined. This difference is due to the nature of non-linearities in the models. On the EF model, the behavior is ruled by few idealized elements (plastic hinges), while on FE model the non-linearities are spread to all the elements; therefore, the transition between the linear and nonlinear phase is much more dilatated, depending on the status of more elements.

Differences can be noticed even in the post-elastic phase, thus inducing major divergencies on displacement capacity, as the FEM analyses provide higher values for ultimate displacement and peak shear capacity, which brings to a brittle failure of the structure. Significant differences can be observed even between the FE models: while the curves coincided in the elastic section due to the equal elastic properties of the materials' model, the post-elastic behavior changed, due to the different non-linear model implemented by the two software: MIDAS curves were characterized by a higher post-elastic stiffness, leading to higher maximum shear values.

The models were also compared on damage evolution (Figure 7). For the EF model, the damage is represented by a color scale legend of the status reached by every element based on the related plastic hinges status, while for FE model, the damage is represented by major principal strain. Firstly, a correspondence between the rigid node elements of EF model and the un-damaged portion of FEM walls can be noticed, thus validating the assumptions of the EF approach. Secondly, all the three models pointed out the major damage located at the piers of the first floor, suggesting the activation of a soft story mechanism, which led to the collapse 
of the structure. The main difference can be observed on the damage at upper levels, as the FE model led to the damage located on the piers of the second floor, while the EF on the third one.
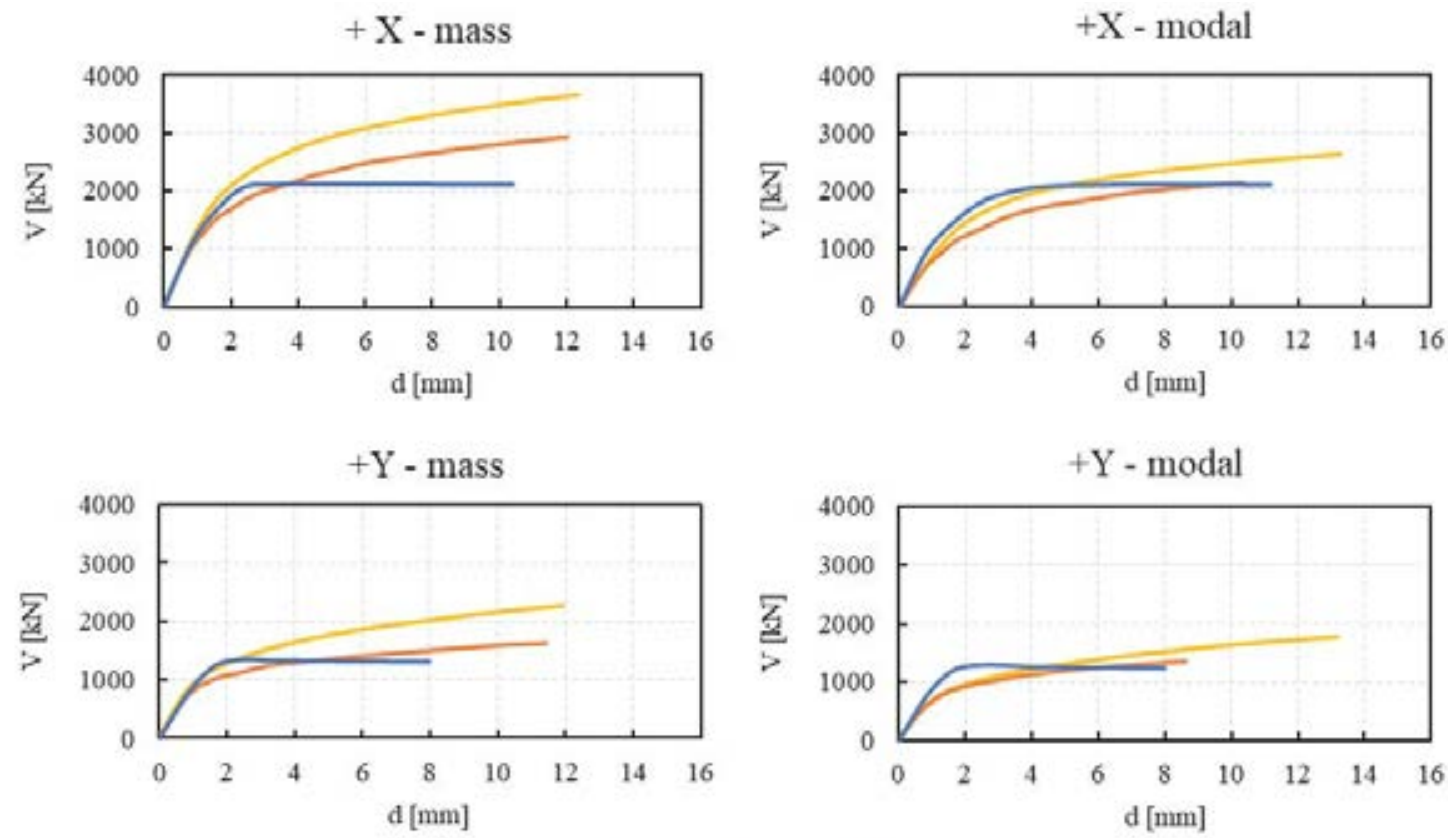

m 3MURI $\equiv$ DIANA $=$ MIDAS

Figure 6: Comparison among pushover curves of different models

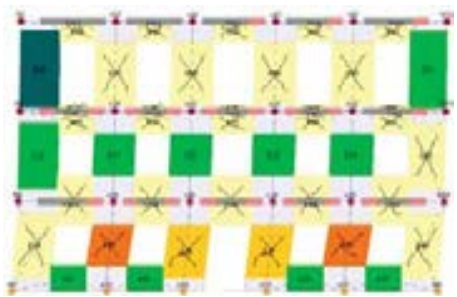

[a]

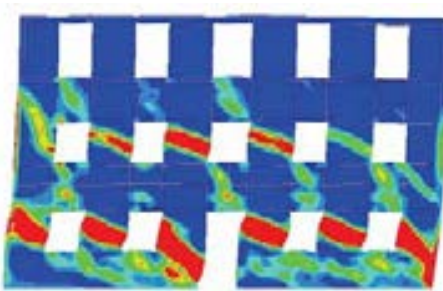

[b]

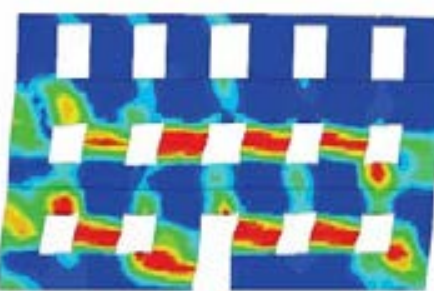

[c]
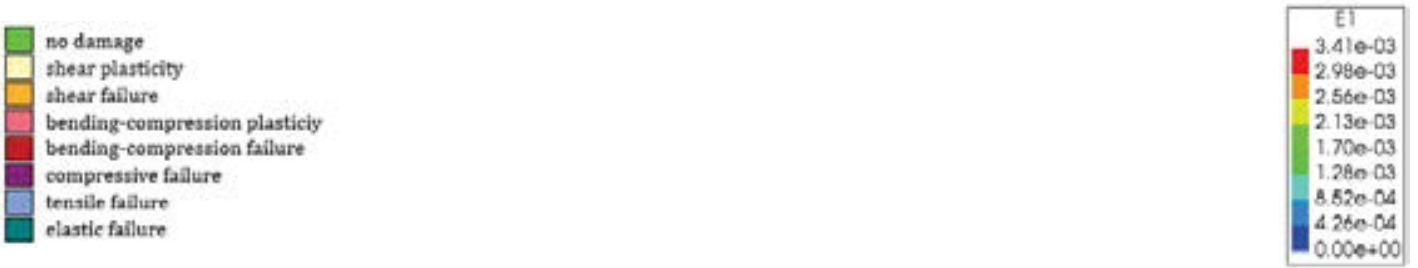

Figure 7: Damage pattern example for each model: 3MURI (a), DIANA (b) and MIDAS (c). Analysis case: Modal X

\subsection{Seismic capacity assessment}

Verifications were carried out following the Italian seismic code [10][18], obtaining the capacity in terms of Near-Collapse PGA $\left(\mathrm{PGA}_{\mathrm{C}}\right)$ for every pushover curve. Resulting PGA capacities of FE models were compared to EF ones $\left(\Delta_{\mathrm{PGA}}\right)$ and reported in Table 4. Results pointed out that the $\mathrm{Y}$ direction is the most vulnerable one, providing lower values of NearCollapse PGA (PGA $)$ ). Comparing the modeling strategies, lower values can be observed for the EF model, especially for the transversal direction analyses, suggesting a more conservative approach. The FE models deliver similar PGA values for Y-direction analyses, while dif- 
ferences emerge from X-direction ones, as MIDAS values are significatively higher than DIANA ones.

\begin{tabular}{c|c|cc|cc}
\hline \multirow{2}{*}{ Analysis } & 3MURI & \multicolumn{2}{|c|}{ DIANA FEA } & \multicolumn{2}{c}{ MIDAS FEA NX+ } \\
\cline { 2 - 6 } & PGA $_{\mathrm{C}}[\mathrm{g}]$ & PGA $[\mathrm{g}]$ & $\Delta_{\mathrm{PGA}}[\%]$ & PGAC $[\mathrm{g}]$ & $\Delta_{\mathrm{PGA}}[\%]$ \\
\hline X Mass & 0.220 & 0.222 & +0.9 & 0.289 & +31.3 \\
Y Mass & 0.125 & 0.187 & +49.6 & 0.189 & +51.2 \\
X Modal & 0.194 & 0.174 & -10.4 & 0.200 & +3.1 \\
Y Modal & 0.104 & 0.114 & +9.6 & 0.118 & +13.5 \\
\hline
\end{tabular}

Table 4: Near-collapse PGA capacities $\left(\mathrm{PGA}_{\mathrm{C}}\right)$ and percentage variation $\triangle_{\mathrm{PGA}}$ on EFM model.

\section{CONCLUSIONS}

In this contribution, different modeling strategies for existing URM buildings have been applied to a representative case study.

The case study was a three-story URM building located in the Italian Alpine region. It has a rectangular plan shape, as well as it is regular in elevation. Lower portion was built using local calcareous stone blocks, while the upper portion was made of hollow clay blocks.

Equivalent Frame (EF) and Finite Element (FE) models were implemented using different software $[9,14,15]$. The comparison of analyses results showed that:

- differences related to the various approaches can be observed, especially in damage evolution and post elastic behavior;

- both EFM and FEM approaches identified the same soft story mechanism involving the first floor's piers, even if differences can be observed in damage pattern among the strategies;

In this study, EFM approach produced more conservative results than FEM ones, providing lower capacity PGA values. Other examples led to controversial results [2][4][7], suggesting that one or other strategy has to be carefully chosen, depending on case study characteristics and analysis purposes; besides its low computational effort, the EFM approach appears to be suitable for seismic assessment of regular building. FE approach is indicated for more irregular structures, which cannot be easily schematized with EF method. They even provide more detailed results, allowing local damage patterns to be better identified, however they require way more computational time.

\section{ACKNOWLEDGEMENTS}

This work was supported by the CORE-WOOD (COmpetitive REpositioning of WOOD sector) Italian project, in the framework of POR-FESR 2014-2020 Line 1 Action 1.1.4 of the Veneto Region.

\section{REFERENCES}

[1] L. Sorrentino, S. Cattari, F. da Porto, G. Magenes, and A. Penna, Seismic behaviour of ordinary masonry buildings during the 2016 central Italy earthquakes, Bull. Earthq. Eng., vol. 17, no. 10, pp. 5583-5607, 2019.

[2] J. A. Kollerathu, S. Krishnachandran, and A. Menon, Modelling and seismic analysis of existing masonry structures, Struct. Anal. Hist. Constr. Anamn. diagnosis, Ther. Con- 
trol. - Proc. 10th Int. Conf. Struct. Anal. Hist. Constr. SAHC 2016, no. February 2017, pp. 257-264, 2016.

[3] E. Quagliarini, G. Maracchini, and F. Clementi, Uses and limits of the Equivalent Frame Model on existing unreinforced masonry buildings for assessing their seismic risk: A review, J. Build. Eng., vol. 10, no. December 2016, pp. 166-182, 2017.

[4] R. Siano, G. Camata, V. Sepe, E. Spacone, P. Roca Fabregat, and L. Pelà, Finite elements vs. equivalent frame models for URM walls in-plane behaviour, in 16th World Conference on Earthquake Engineering 16WCEE 2017, 2017, no. December, pp. 1-11.

[5] M. R. Valluzzi, M. Salvalaggio, and L. Sbrogiò, Repair and conservation of masonry structures, in Numerical Modeling of Masonry and Historical Structures, vol. 66, Elsevier, 2019, pp. 201-235.

[6] P. B. Lourenço, Structural Masonry Analysis: Recent Developments and Prospects, $J$. Chem. Inf. Model., vol. 53, no. 2004, p. 160, 2008.

[7] F. Clementi, V. Gazzani, M. Poiani, and S. Lenci, Assessment of seismic behaviour of heritage masonry buildings using numerical modelling, J. Build. Eng., vol. 8, pp. 29-47, 2016.

[8] A. Borri and A. De Maria, Indice di Qualità Muraria (IQM): correlazione con le caratteristiche meccaniche e livelli di conoscenza, ReLuis 2015 - Linea Costr. Muratura, pp. 45-63, 2015. (in Italian)

[9] S.T.A. DATA, Manuale d'uso 3Muri ver. 10.9.0.

[10] S. Lagomarsino, A. Penna, A. Galasco, and S. Cattari, TREMURI program: An equivalent frame model for the nonlinear seismic analysis of masonry buildings, Eng. Struct., vol. 56, pp. 1787-1799, 2013.

[11] Ministero delle Infrastrutture e dei Trasporti, D.M. 17 gennaio 2018, “Aggiornamento delle «Norme tecniche per le Costruzioni»»", 2018. (in Italian)

[12] S. Bracchi, M. Rota, A. Penna, and G. Magenes, "Consideration of modelling uncertainties in the seismic assessment of masonry buildings by equivalent-frame approach," Bull. Earthq. Eng., vol. 13, no. 11, pp. 3423-3448, 2015.

[13] CNR-DT 212/2013. Istruzioni per la Valutazione Affidabilistica della Sicurezza Sismica di Edifici Esistenti 2014. (in Italian)

[14] TNO Building and Construction Research, "DIANA - Finite Element Analysis User's Manual - Release 10.4”, 2020

[15] MIDAS Engineering, "MIDAS FEA NX User Manual”, 2019

[16] M. Petrangeli and J. Ožbolt, "Smeared Crack Approaches-Material Modeling," J. Eng. Mech., vol. 122, no. 6, pp. 545-554, 1996. 
[17] L. Bejarano-Urrego, E. Verstrynge, G. Giardina, and K. Van Balen, "Crack growth in masonry: Numerical analysis and sensitivity study for discrete and smeared crack modelling," Eng. Struct., vol. 165, pp. 471-485, 2018.

[18] C.S.LL.PP, Circolare 21 gennaio 2019, n. 7, "Circolare applicativa delle nuove Norme Tecniche per le Costruzioni approvate con D.M. 17 gennaio 2018”, 2019. (In Italian) 